\title{
The role of new technologies in understanding the building energy performance: A comparative study
}

\author{
Ola Alhaj Hasan ${ }^{\mathrm{a}}$, Didier Defer ${ }^{\mathrm{b}} *$ \\ ${ }^{a}$ LGCgE, IUT de Béthune, 62400 Béthune, France \\ ${ }^{b}$ LGCgE, Artois University, 62400 Béthune
}

\begin{abstract}
This paper aims to understand the most important factors affecting the building energy performance as well as the role of a high performant construction in reducing the energy consumption. To be able to carry out this study, some new technologies such as a 3D scanner and energy simulation software were used. The results of the study show that a performant construction doesn't necessarily optimize the consumption. Other factors mainly related to the occupation are playing a big role in the final consumption.
\end{abstract}

Keywords: Energy performance, building, 3D scan, BIM

\section{Introduction}

Buildings nowadays are the $1^{\text {st }}$ energy consumer of all sectors especially due to their heating needs [1]. In the last few years, with the raising awareness about energy consumption, a special interest in building energy performance appeared.

Therefore, a large variety of tools and software were developed. These tools are all used to better understand and analyse the building thermal behaviour [2,3].

However, no matter which software is used to simulate a building, the simulation results are most probably different from the real state of the building due to many reasons and factors related to building dynamics, occupants' behaviour and even plan availability [4].

In parallel to all these theoretical and analytical tools, the experimental method is also very important, especially for old buildings where we don't have many details.

Also the experimental method is very useful to develop new materials and conception methods [5].

This paper aims mainly to carry out a comparison between 3 main consumption indicators:

1- The target consumption of the building (defined in the conception phase) and limited by country regulations.

2- The consumption resulting by simulation using a certified software.

3- The real consumption of the building.

To be able to do this comparison, some new technologies where used to carry out the simulations.

\section{Building Energy Performance}

Building energy performance is a very important criteria to be evaluated when studying a building and trying to optimize its energy consumption. An energy performant building is a building that would use less energy without compromising the thermal comfort or the regular usages defined in the building conception. Estimating the building energy performance is a very hard mission because too many factors can affect it.

\footnotetext{
* Manuscript received June 23, 2018; revised April 14, 2019.

Corresponding author. Tel.: +33611966101; E-mail address: ola.alhajhasan@univ-artois.fr.

doi: $10.12720 /$ sgce.8.4.397-401
} 
The main factor that would guarantee the potential high performance of the building is the construction itself. Construction materials as well as construction and finishing quality are primordial factors to have a good energy performance. But these are not necessarily enough to guarantee it.

The usage of the building, the orientation and also the occupants' behaviour are also very important factors to be taken into consideration.

\section{Case Study}

\subsection{Fleming centre building}

In order to realise the comparison between the theoretical, the conception and the real energy consumption, an office building is studied as a demonstrator.

This office building is called "Centre Fleming" with a surface of 722 square meters and is situated in the north of France.

This building has been transformed into a start-up incubator on 2000. The local community in charge of the building has the energy optimisation as a main priority, that's why the building served also to test new building materials. Therefore, the facades of the building are composed from 3 different materials.

The real energy consumption of the building was also collected.

\subsection{Building simulation}

As mentioned before, many software have been developed in the recent years. The main objective of these software is to calculate the energy consumption of the building and compare different materials. In France there are a few certified programs that can achieve the thermal simulation of the building. The usage of one of these programs is a very important condition to obtain the construction or renovation permission.

The software that we are going to use in this research is called ARCHIWIZARD. It is specialized software in the thermal studies of buildings. The regulation is also registered and being compared in each simulation in order to verify the conformity of the building to French thermal regulations (RT2012) [9,10].

In order to be able to study the building using Archiwizard, a 3D model of the building is needed. In the case of this building that has been renovated a few years ago, the available plans are not updated according to the renovation procedure which means that we couldn't use them to build a 3D model. Hence, another tool has been used in order to realize a précised up to date 3D model of the building. This tool is a 3D scanner which is one of the last innovative technologies in the construction area.

\subsection{Building $3 D$ scan}

The 3D scan of the building was realized using a scanner developed by the German society Leica (Fig. 1).
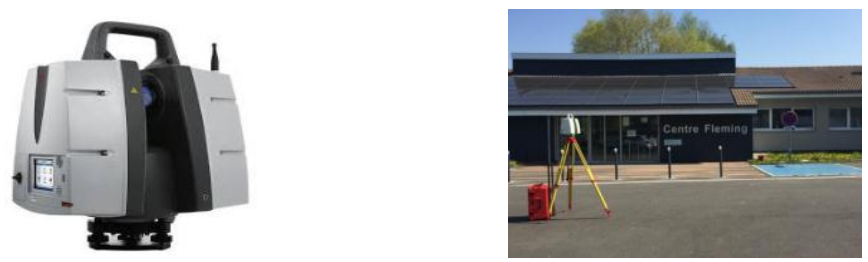

Fig. 1. The 3D scanner and the scanning process.

The scanner provides different precisions varying between ( $\pm 15 \mathrm{~mm}$ to $\pm 4 \mathrm{~mm}$ ). It is able to capture 1 million points per second over a distance of $1 \mathrm{KM}$. The concept of a 3D scanner is to build a 3D point cloud by sending a laser from the $360^{\circ}$ turning head of the scanner that is measuring the distance of every point from the scanner head.

In order to start the scan, we have first to fix the so called "scan stations". The main principle to 
choose these stations is to have all the facades of the building covered by these stations with at least one façade in common between a station and its precedent (Fig. 2.).

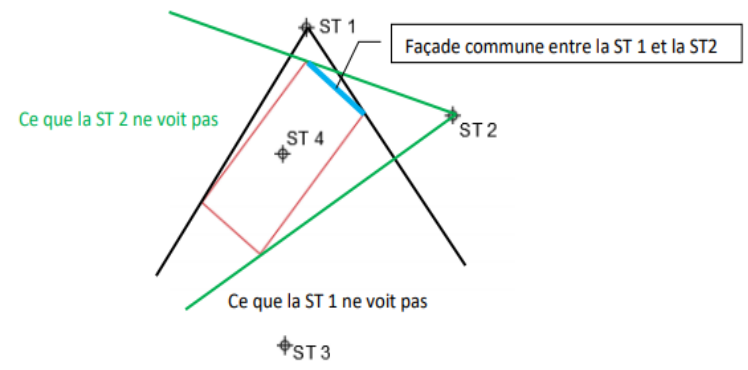

Fig. 2. Stations choice concept.

Choosing the scan stations is a very important step because according to the choice the work can be optimised and minimised. While on the other hand, a bad choice would also double the work and cause a loss of time and money.

When starting the scanner and adding a new project we have two choices:

- Georeferenced stations: mainly used for the records of the building in case of an official or administrative project.

- Auto referenced stations: Considering the first station as the 0 point and referencing all the next stations according to it (which takes less time).

We chose the second option in order to save the time in the scan work (Fig. 3).
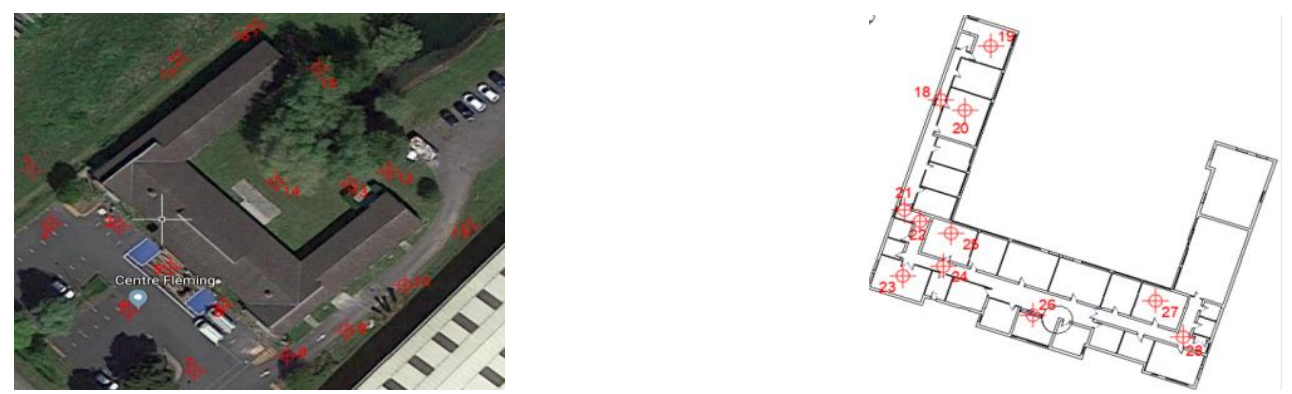

Fig.3. Chosen stations in the building.

\subsection{Building $3 D$ scan Assembly and draw}

After achieving the scans, an assemblage work is to be done using a special software CYCLONE. The data from the scanner is collected and transferred into CYCLONE that will automatically analyze the positions of stations according to each other on the coordinate system (Figure.4.).

The data in CYCLON is a point cloud that needs to be drawn into a 3D drawing software.

Therefore, we imported the point cloud from CYCLON to REVIT in order to draw the final 3D model of the building.
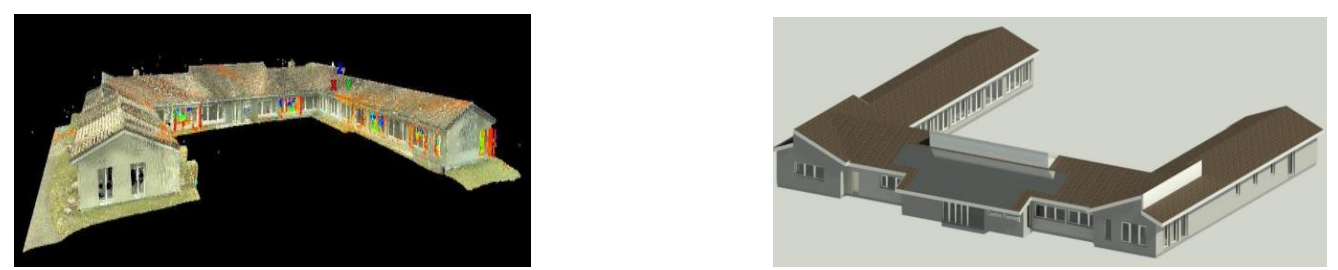

Fig .4. Scan results when assembled by CYCLONE and finalized by REVIT 


\subsection{Building thermal simulation}

After obtaining the 3D model of the building, the thermal simulation can be done using the thermal simulator ARCHIWIZARD. From REVIT, an export of the 3D model to ARCHIWIZARD is done. As mentioned before, 3 different compositions of the facades are being tested in this building. These compositions are then to be created in ARCHIWIZARD as in Figure.5.
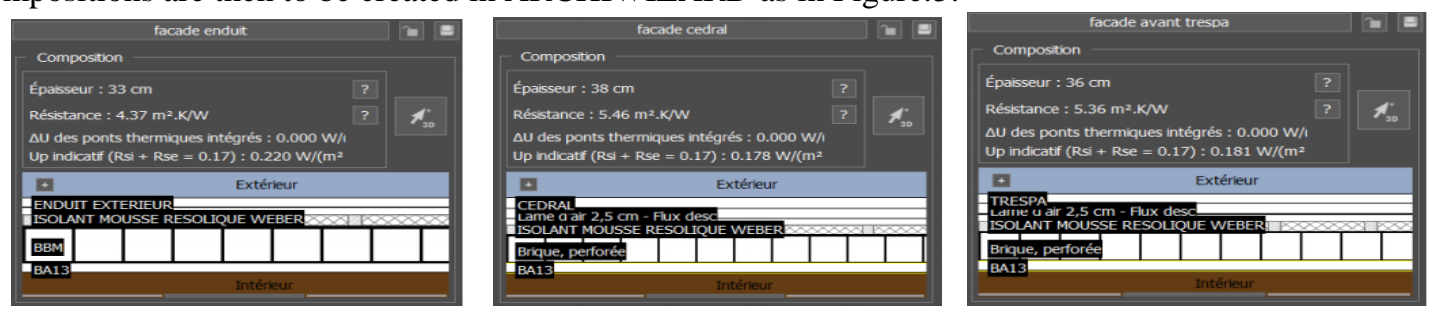

Fig. 5. Types of façade compositions.

After defining all the construction compositions, the usage and the heating hours of the building. The simulation is run. Simulation results appear in Table 1.

Table 1. Key numbers from the building simulation.

\begin{tabular}{|c|c|c|c|c|c|c|c|c|c|c|c|c|c|}
\hline Cumuls (kWh) & Jan & Fev & Mar & Avr & Mai & Juin & Jul & Aout & Sep & Oct & Nov & Déc & Annuel \\
\hline Contribution solaire & 1904 & 2339 & 3980 & 5295 & 6389 & 6489 & 7042 & 6192 & 4911 & 3533 & 1637 & 1543 & 51255 \\
\hline Apports internes & 4305 & 3775 & 4159 & 3510 & 4305 & 3982 & 3982 & 2460 & 3836 & 4305 & 4128 & 3453 & 46200 \\
\hline Transmission par fenveloppe & -7001 & -5870 & -7176 & -6895 & -6061 & -4692 & -4176 & -3634 & -5069 & -6300 & -5741 & -5982 & -68598 \\
\hline Pertes par renouvelement d'air & -1654 & -1358 . & -1894 & -1682 & -1510 & -1019 & -858 & .734 & -1203 & -1665 & -1547 & -1483 & -16608 \\
\hline $\begin{array}{l}\text { Rayonnement vers la voûte } \\
\text { celeste }\end{array}$ & -220 & -223 & -287 & -256 & -252 & -247 & -247 & -211 & -257 & -249 & -196 & -255 & -2900 \\
\hline Contribution de féclarage & 1523 & 1282 & 1201 & 966 & 882 & 846 & 840 & 929 & 978 & 1377 & 1513 & 1453 & 13789 \\
\hline Besoin de chauffage & 1264 & 94 & 0 & 0 & 0 & 0 & 0 & 0 & 0 & 0 & 111 & 1259 & 2729 \\
\hline Besoin de refroidissement & 0 & 0 & 0 & -880 & -3737 & -5341 & -6588 & -5012 & -3214 & -994 & 0 & 0 & -25766 \\
\hline
\end{tabular}

\subsection{Results analysis}

The thermal regulations in France require mainly the respect of the so-called: Bioclimatic needs.

These needs are calculated depending on several factors as follow: The region of situation, the heat, and lightning and ventilation consumption per square meter, the usage of the building.

The bioclimatic needs of the building are then compared to the so called "maximum bioclimatic need" which is defined in official tables according to the altitude, region and location of the building. This indicator is given in points and that's why the needs of the building are also transformed into points according to the energy source. According to these tables, the maximum bio-climatic needs allowed for our building should not exceed 77 points. The simulation results show that the building is within the Thermal Regulations 2012 range of consumption with 66 points. However, the problem is that the real consumption of the building is showing a much higher bioclimatic need of 85 points. This is calculated according to the real consumption of the building.

\section{Conclusion}

As mentioned before, the main objective of this study is to achieve a comparison between the regulation/ Simulation/Actual consumption of the building.

According to this study, the simulation results give a very optimistic consumption, which is quite inferior to the Regulated limits. The problem is now that, in Actual life, the building is consuming way more than the simulation or the regulated limit. This difference in the actual and the simulated consumption is more likely due to the building usage and not the construction itself.

In fact, a very performant construction doesn't necessarily lead to an optimized consumption.

The usage of the building can widely affect its consumption. Therefore, the next step of this research is to study this usage by instrumenting the building with sensors of temperature, $\mathrm{CO}_{2}$, presence, humidity. 
These measures are necessary to figure out this huge difference between the planned and the actual consumption of the building.

\section{References}

[1] Hasan OA, Didier D, and Isam S. A simplified building thermal model for the optimization of energy consumption: Use of a random number generator. Energy and Buildings, 2014; 82: 322-329.

[2] Reddy TA. Literature review on calibration of building energy simulation programs: Uses, problems, procedures, uncertainty, and tools. ASHRAE transactions, 2006; $112: 226$.

[3] Crawley, Drury B, et al. Contrasting the capabilities of building energy performance simulation programs. Building and environment. 2008; 43(4) : 661-673.

[4] Jenkins D, Liu Y, and Peacock AD. Climatic and internal factors affecting future UK office heating and cooling energy consumptions. Energy and Buildings, 2008; 40(5): 874-881.

[5] Sadineni, Suresh B, Srikanth M, and Robert FB. Passive building energy savings: A review of building envelope components. Renewable and Sustainable Energy Reviews, 2011; 15(8): 3617-3631.

[6] Wu HC, and Peijiang S. New building materials from fly ash-based lightweight inorganic polymer. Construction and Building Materials, 2007; 21(1): 211-217.

[7] Reddy, Venkatarama BV, and Jagadish KS. Embodied energy of common and alternative building materials and technologies. Energy and Buildings, 2003; 35(2): 129-137.

[8] Pappu A, Mohini S, and Shyam RA. Solid wastes generation in India and their recycling potential in building materials. Building and Environment, 2007;42(6): 2311-2320.

[9] Le MY, and Machner R. Impact of the new French thermal regulation on office indoor environment: combine innovative cooling technology and high acoustic demand. Euronoise Prague (2012).

[10] Charrier S, Jocelyne P, and Alexis H. The airtightness quality management approach in France-Assessment after more than five years of operation. International Journal of Ventilation, 2014; 13(2): 125-140. 